\begin{tabular}{|c|l|}
\hline Title & Residual ferrite formation in 12CrODS steels \\
\hline Author(s) & Ukai, S.; Kudo, Y.; Wu, X.; Oono, N.; Hay ashi, S.; Ohtsuka, S.; Kaito, T. \\
\hline Citation & $\begin{array}{l}\text { Journal of nuclear materials, 455(1-3), 700-703 } \\
\text { https://doi.org/_0.1016/.jnucmat.2014.09.038 }\end{array}$ \\
\hline Issue Date & 2014 12 \\
\hline Doc URL & http://hdl.handle.net/2115/58009 \\
\hline Type & article(author version) \\
\hline File Information & [16-385]_(Ukai)_manuscript.pdf \\
\hline
\end{tabular}

Instructions for use 


\title{
Residual Ferrite Formation in 12CrODS Steels
}

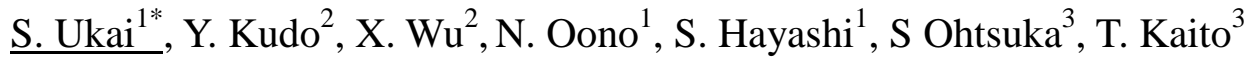 \\ ${ }^{1}$ Materials Science and Engineering, Faculty of Engineering, Hokkaido University: \\ N13, W-8, Kita-ku, Sapporo 060-8628, Japan \\ ${ }^{2}$ Materials Science and Engineering, Graduate School of Engineering, Hokkaido \\ University: N13, W-8, Kita-ku, Sapporo 060-8628, Japan \\ 3 Japan Atomic Energy Agency: 4002 Narita, O-arai, Ibaraki 311-1393, Japan
}

\begin{abstract}
Increasing $\mathrm{Cr}$ content from 9 to 12 mass \% leads to superior corrosion and high-temperature oxidation resistances, but usually changes microstructure from martensite to full-ferrite. Alloy design was conducted for 12CrODS steels to modify their structure to the martensite-base matrix, since the transformable martensititic ODS steels have superior processing capability by using $\alpha / \gamma$ phase transformation. The two types of ferrite are included; the equilibrium ferrite is predictable from the equilibrium phase diagram. Formation of the metastable residual ferrite was assessed through pinning of $\alpha / \gamma$ interfacial boundaries by oxide particles as well as chemical driving force for the $\alpha$ to $\gamma$ transformation.
\end{abstract}

[Key Word] ODS, 12Cr, Martensite, Full-ferrite, Residual ferrite, $\alpha / \gamma$ phase transformation, Pinning force, Chemical driving force, Fusion materials

*Corresponding Author: Shigeharu Ukai

Postal address : N13, W-8, Kita-ku, Sapporo 060-8628, Japan

Telephone number $\quad$ : + +81-11-706-6355

E-mail address : s-ukai@eng.hokudai.ac.jp 


\section{Introduction}

As candidate materials for the advanced fission and fusion materials, the $9 \mathrm{Cr}$ oxide-dispersion-strengthened (ODS) steels have an advantage for controlling processing-fabrication routes by an $\alpha / \gamma$ phase transformation, however they exhibit inferior corrosion and high-temperature oxidation resistance. Increasing chromium content improves this disadvantage, but amount of chromium addition induces embrittlemet due to $\alpha$ precipitate [1, 2]. Therefore, we selected 12 mass \% Cr ODS steels within a limited amount of chromium addition [3]. These steels are usually full-ferrite. In this study, the transformable martensitic base 12CrODS steels are designed to lead to better processing formability by the $\alpha / \gamma$ transformation. For transformable 9CrODS steels, it is known that their structure is a dual phase composed of tempered martensite and ferrite[4-6], although the full-tempered martensite is predicted in the equilibrium phase diagram. This ferrite is designated as a metastable residual ferrite, and it is also known that the residual ferrite significantly improves the high-temperature strength in 9CrODS steels [7-12]. The structure of martensitic base 12CrODS steels is, therefore, investigated, focusing on residual ferrite formation improving high-temperature strength. The microstructural change induced by increasing chromium content from 9 to 12 mass \% was evaluated in terms of SEM and TEM observation, hardness measurement and thermodynamic analysis.

\section{Experimental Procedure}

Pure elemental powders of iron (99.5 mass\%, 45-100 $\mu \mathrm{m})$, carbon $(99.7$ mass\%, 5

$\mu \mathrm{m})$, chromium (99.9 mass\%, under $250 \mu \mathrm{m}$ ), nickel (99.9 mass $\%$, under $250 \mu \mathrm{m}$ ), 
tungsten (99.9 mass\%, 4.5-7.5 $\mu \mathrm{m})$ and titanium (99.7 mass\%, under $150 \mu \mathrm{m})$ were mechanically alloyed (MAed) together with $\mathrm{Y}_{2} \mathrm{O}_{3}$ powder (99.9 mass\%, $20 \mathrm{~nm}$ ) for $48 \mathrm{~h}$ in an argon gas atmosphere using a planetary-type ball mill (Fritsch P-5). The rotation speed is $450 \mathrm{rpm}$ and powder to ball ratio is $1 / 10$.

The MAed powders were consolidated by spark plasma sintering (SPS) at $1100{ }^{\circ} \mathrm{C}$ and $44 \mathrm{MPa}$ for $2 \mathrm{~h}$. A size of the consolidated specimens is $12 \mathrm{~mm}$ in diameter and $40 \mathrm{~mm}$ in height, and this cylindric type of specimens were embedded into plate made of stainless steel (SS). The SS plates containing 12CrODS steel cylinders were kept at temperature of $1150{ }^{\circ} \mathrm{C}$ in the electric furnace, and they were hot-rolled (HRed) up to total reduction rate of $77 \%$, and followed by air-cooling (AC) to room temperature at a cooling rate of about $3,400^{\circ} \mathrm{C} / \mathrm{h}$. Some of the hot-rolled specimens were subsequently normalized at $1050^{\circ} \mathrm{C}$ for $1 \mathrm{~h}$ and tempered at $800{ }^{\circ} \mathrm{C}$ for $1 \mathrm{~h}(\mathrm{~N}-\mathrm{T})$.

The composition of $12 \mathrm{CrODS}$ steels was set to be $12 \mathrm{Cr}-0.15 \mathrm{C}-1.5 \mathrm{~W}-0.3 \mathrm{Ti}-$ $0.35 \mathrm{Y}_{2} \mathrm{O}_{3}$ (mass \%) with parameters of $0,0.5$ and 1.0 mass \% in nickel content, where three specimens fabricated are designated as $0 \mathrm{Ni}, 0.5 \mathrm{Ni}$ and $1 \mathrm{Ni}$ specimens. The phase diagram of $12 \mathrm{Cr}-0.15 \mathrm{C}-1.5 \mathrm{~W}-0.3 \mathrm{Ti}$ system was calculated by means of Pandat code as a function of nickel content. As shown in Fig. 1, 1Ni specimen belongs to the single $\gamma$-austenite, and $0.5 \mathrm{Ni}$ and $0 \mathrm{Ni}$ specimens are composed of dual $\alpha$ and $\gamma$ phases at the 
normalizing temperature of $1050{ }^{\circ} \mathrm{C}$. The fraction of $\alpha$ and $\gamma$ phases for $0.5 \mathrm{Ni}$ and $0 \mathrm{Ni}$ specimens can be also predicted by Pandat code. The metallographic specimens were polishing with 400-4000 emery paper, $1 \mu \mathrm{m}$ diamond paste and alumina colloidal silica, and microstructure was analyzed by means of JEOL JSM-6500F field-emission scanning electron microscope (FE-SEM). The micro Vickers hardness was measured using a Shimazu HVM-2 micro hardness tester. The specimens for transmission electron microscopy (TEM) were prepared by electro-chemically polishing using a Tenupol-5 and a solution of perchloric acid: acetic acid $=1: 19$. The size and distribution of the dispersed oxide particles were analyzed by a LaB6 type JEM-2010 with an acceleration voltage of $200 \mathrm{kv}$.

\section{Results}

The SEM photos of the $0 \mathrm{Ni}, 0.5 \mathrm{Ni}$ and $1 \mathrm{Ni}$ specimens after normalizing at $1050{ }^{\circ} \mathrm{C}$ for $1 \mathrm{~h}$ are represented in Fig.2, where the flat surface and wavy surface areas correspond to ferrite and martensite, respectively, as shown by arrows. It can be seen that three specimens are composed of dual phases, ferrite and martensite. Even though the single $\gamma$-austenite is predicted for $1 \mathrm{Ni}$ specimen at $1050{ }^{\circ} \mathrm{C}$ shown in Fig.1, the ferrite with the flat surface exists; thus this ferrite corresponds to the metastable residual 
ferrite. The structure of all of specimens is martensite-base, and an area fraction of the ferrite measured by image analyses led to $32 \%$ for $0 \mathrm{Ni}, 19 \%$ for $0.5 \mathrm{Ni}$ and $10 \%$ for 1Ni specimens.

The micro Vickers hardness measurement was conducted for these specimens normalized at $1050{ }^{\circ} \mathrm{C}$ for $1 \mathrm{~h}$ and followed by tempering at $800{ }^{\circ} \mathrm{C}$ for $1 \mathrm{~h}$. Their results are plotted in relation to the ferrite fraction in Fig. 3: the hardness increases with increasing the ferrite fraction. It is well known that the ferrite is softer than the tempered martensite, so increasing ferrite fraction induces decrease of hardness in the conventional ferrite-martensitic steels. Our results are opposite to this general trend. This reason is ascribed to dispersion strengthening of oxide particles in both phases. It was reported in our previous study on 9CrODS steels [5] that a few nm size oxide particles are finely dispersed in the ferrite phase. Inversely their size in the martensite phase is coarser in association with $\alpha / \gamma$ reverse transformation that could disturb the interfacial coherency between oxide particle and matrix, and thus could coarsen the oxide particles to minimize the interfacial energy [13]. Based on above previous study, the ferrite fraction measured by image analyses of the SEM is reasonable for $0 \mathrm{Ni}, 0.5 \mathrm{Ni}$ and $1 \mathrm{Ni}$ specimens.

The ferrite fraction for the different nickel content estimated by image analyses of 
SEM photos of Fig. 2 is represented by solid circles in Fig. 4. This ferrite includes the equilibrium ferrite as well as metastable residual ferrite. Both ferrites can't be separated by the SEM photos, however the equilibrium ferrite can be thermodynamically predicted by means of Pandat code. Their results are shown by the solid squares in Fig. 4. The difference of both ferrite fraction, therefore, corresponds to the metastable residual ferrite. This fraction slightly decreases with increasing nickel contents.

\section{Discussion}

The formation process of the residual ferrite is discussed for 12CrODS steels. Based on the computed phase diagram shown in Fig. 1, $\mathrm{M}_{23} \mathrm{C}_{6}$ carbide in $\alpha$ ferrite is decomposed when normalized at $1050{ }^{\circ} \mathrm{C}$, and $\gamma$ phase is concomitantly stabilized. The free energies of the $\alpha$ and $\gamma$ phases predicted by Pandat code at $1050{ }^{\circ} \mathrm{C}$ is illustrated as $G^{\alpha}$ and $G^{\gamma}$ in Fig. 5 as a function of carbon content. The $\alpha$ phase containing 0.017 mass \% carbon and $\gamma$ phase containing 0.109 mass \% carbon are mutually equilibrium by the common tangent line. These points are indicated by A and B. Focusing on a process of $\gamma$ phase formation from $\alpha$ phase, however, the carbon 
content around the carbide increases, when the carbide precipitates are decomposed. For instance, at pint $\mathrm{C}$, the chemical driving force for the $\gamma$ phase formation from $\alpha$ phase corresponds to distance B-D by making tangential line at $\mathrm{C}$ on the free energy curve of $\alpha$ phase, $\mathrm{G}^{\alpha}$.

The TEM photographs of the oxide particle are shown in Fig. 6 for $0 \mathrm{Ni}, 0.5 \mathrm{Ni}$ and $1.0 \mathrm{Ni}$ specimens. Average radius of the oxide particles is about $4 \mathrm{~nm}$; thus pinning force by oxide particles against movement of the $\alpha / \gamma$ interface was estimated to be 8 $\mathrm{MJ} / \mathrm{m}^{3}$, according to following equation [14];

$$
F=\frac{3}{4} \cdot \frac{\sigma \cdot f^{2 / 3}}{r}
$$

where $\sigma$ is $\alpha / \gamma$ interfacial energy $\left(0.56 \mathrm{~J} / \mathrm{m}^{2}\right)$ [15], $r$ is radius and $f$ is volume fraction of the oxide particles. This pinning force by the oxide particles is shown by the shade in Fig. 5. In this case, pinning force exceeds the chemical driving force for $\alpha$ to $\gamma$ phase transformation, implying that some of the ferrite retain at the normalizing condition. This ferrite was designated as the residual ferrite. For 12CrODS steels, transformable martensite-base structure was constructed with respect to the nickel content, and the formation of the equilibrium ferrite and the metastable residual ferrite are able to be designed in terms of the equilibrium phase diagram and thermodynamic assessment. 


\section{Conclusion}

The results obtained in this study are summarized as follows;

(1) Alloy design was conducted for 12CrODS steels, and its structure was successfully modified from full-ferrite to the transformable martensitic matrix containing ferrite. This ferrite consists of the equilibrium ferrite and the metastable residual ferrite.

(2) The fraction of the equilibrium ferrite is predictable on the basis of computed equilibrium phase diagram. Formation of the residual ferrite was evaluated through pinning of $\alpha / \gamma$ interfacial boundaries by oxide particles as well as chemical driving force for $\alpha$ to $\gamma$ transformation by thermodynamic assessment.

\section{Reference}

[1] C. Capdevila, M.K. Miller, K.F. Russell, J. Chao, J.L. Gonz'alez-Carrasco, Materials Science and Engineering A 490 (2008) 277-288.

[2] C. Capdevila, M.K. Miller, I. Toda, J. Chao, Materials Science and Engineering A 527 (2010) 7931-7938.

[3] S. Ohtsuka, T. Kaito, T. Tanno, Y. Yano, S. Koyama, K. Tanaka, J. Nucl. Mater. 442 (2013) S89-S94. 
[4] S. Ukai, M. Fujiwara: J. Nucl. Mater. 307-311 (2002) 749-757.

[5] M. Yamamoto, S. Ukai , S. Hayashi , T. Kaito , Satoshi Ohtsuka, J. Nucl. Mater. 417 (2011) 237-240.

[6] S. Ukai, T. Kaito, S. Otsuka, T. Narita, M. Fujiwara, T. Kobayashi, ISIJ Int. 43 (12) (2003) 2038-2045.

[7] S. Ohtsuka, S. Ukai, M. Fujiwara, H. Sakasegawa, T. Kaito, T. Narita: J. Nucl. Mater. 367-370 (2007) 160-165.

[8] S. Ohtsuka, S. Ukai, M. Fujiwara, T. Kaito, T. Narita: J. Nucl. Mater. 329-333 (2004) 372-376.

[9] S. Ohtsuka, S. Ukai, M. Fujiwara: J. Nucl. Mater. 351 (2006) 241-246.

[10] S. Ukai, S. Ohtsuka: Energy Mater. 2 (1) (2007) 26-35.

[11] M. Yamamoto, S. Ukaia, S. Hayashi, T. Kaito and S. Ohtsuka: Materials Science and Engineering A 527 (2010) 4418-4423.

[12] S.Ukai, S.Ohtsuka, T.Kaito, H.Sakasegawa, N.Chikata and S.Hayashi: Materials Science and Engineering A 510-511 (2009) 115-120.

[13] S. Ukai et al : Metal, Ceramic and Polymeric Composites for Various Uses, Published by InTech, 2011, ISBN 978-953-307-353-8.

[14] T. Nishizawa, I. Ohnuma, K. Ishida, Mater. Trans. 38 (11) (1997) 920-956. 
[15] J.W. Marton, R.D. Doherty, Stability of Microstructure in Metallic Systems,

Cambridge University Press, 1976. 173. 


\section{Figure Caption}

Fig. 1 Computed phase diagram of Fe-12Cr-0.15C-1.5W-0.3Ti as a function of nickel content.

Fig. 2 SEM photographs of the fabricated specimens after normalizing at $1050{ }^{\circ} \mathrm{C}$ for $1 \mathrm{~h}$.

Fig. 3 Vickers hardness vs. ferrite fraction of the fabricated specimens after normalizing at $1050{ }^{\circ} \mathrm{C}$ for $1 \mathrm{~h}$ followed by tempering at $800{ }^{\circ} \mathrm{C}$ for $1 \mathrm{~h}$.

Fig. 4 The ferrite fraction vs. nickel content evaluated by SEM microstructure (total ferrite) and Pandat code (equilibrium ferrite). Difference of both ferrite fraction corresponds to the fraction of the metastable residual ferrite.

Fig. 5 Schematic illustration of free energy change during $\gamma$ phase formation from the $\alpha$ phase at normalizing temperature of $1050{ }^{\circ} \mathrm{C}$. The chemical driving force for $\gamma$ phase formation is shown by B-D, and pinning force is shown by shade.

Fig. 6 TEM micrographs of the oxide particles. 


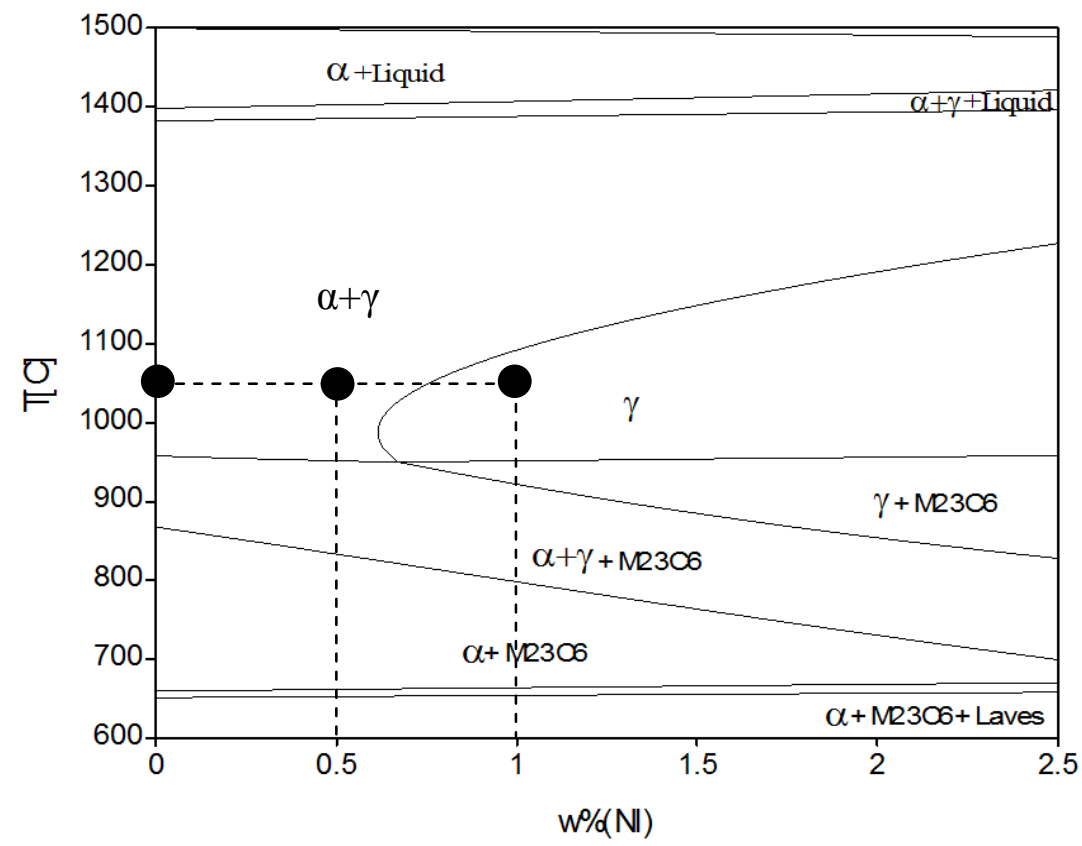

Fig. 1 Shigeharu Ukai, one column 


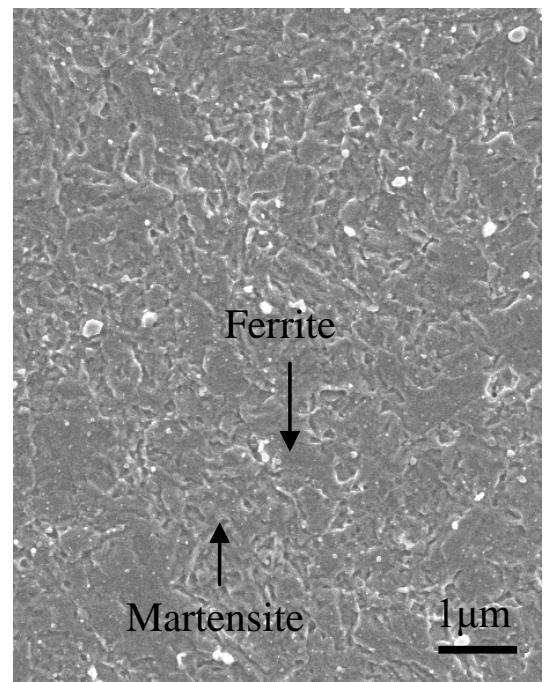

0 mass $\% \mathrm{Ni}$

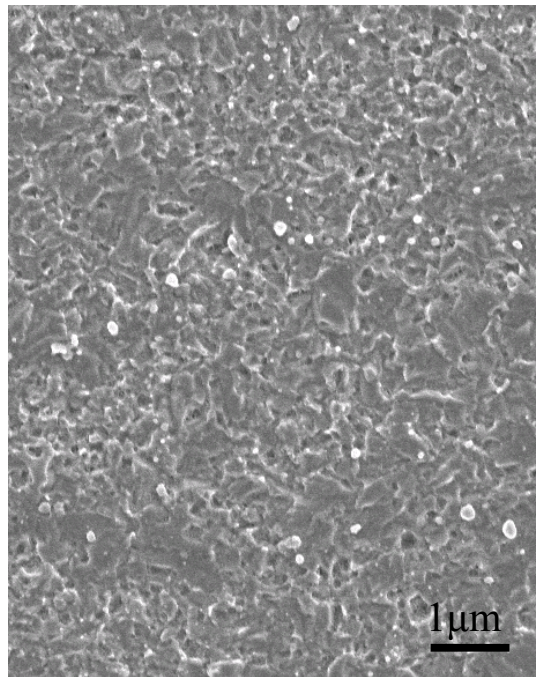

0.5 mass \%

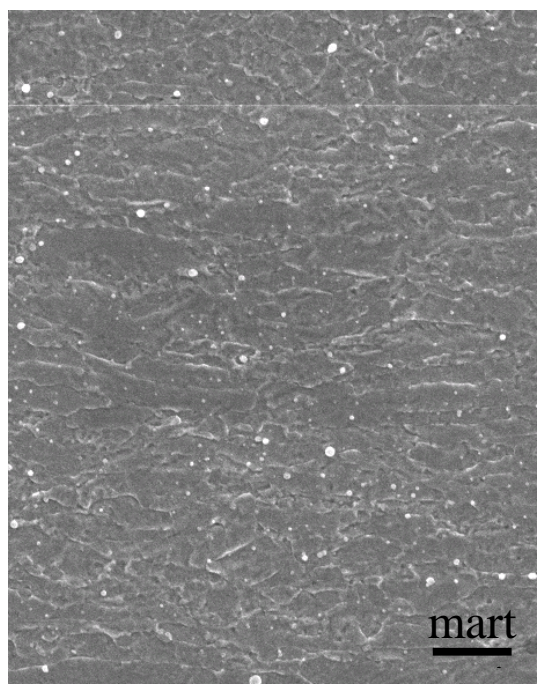

1.0 mass $\% \mathrm{Ni}$

Fig. 2 Shigeharu Ukai, two column 


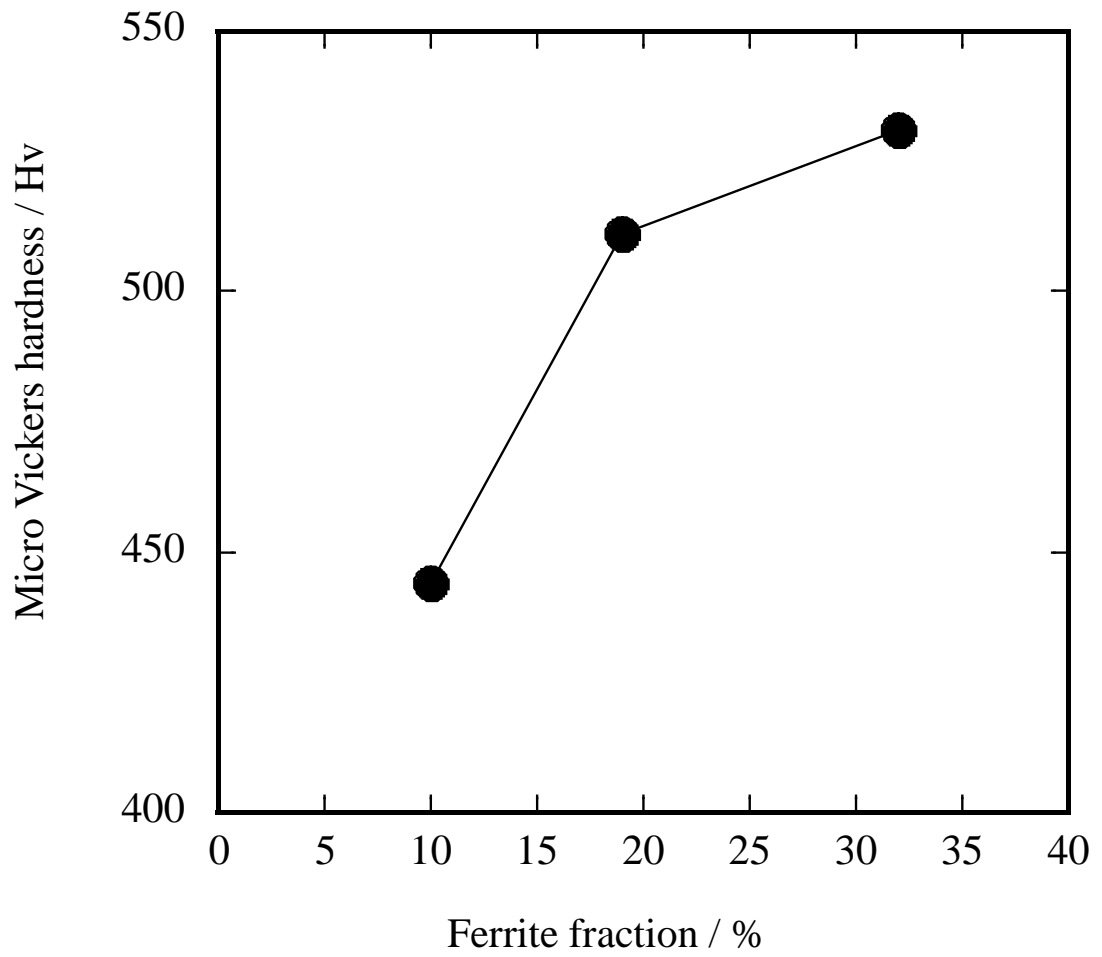

Fig. 3 Shigeharu Ukai, one column 


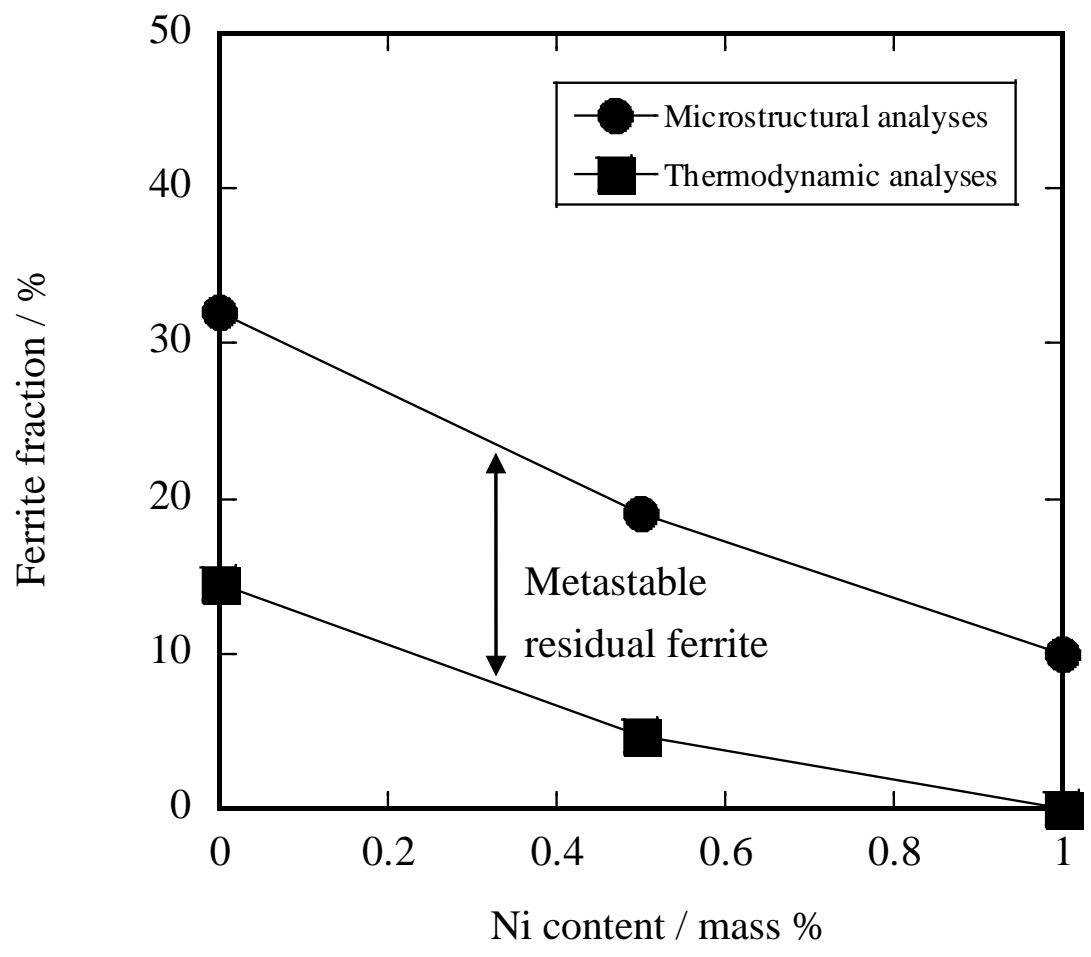

Fig. 4 Shigeharu Ukai, one column 


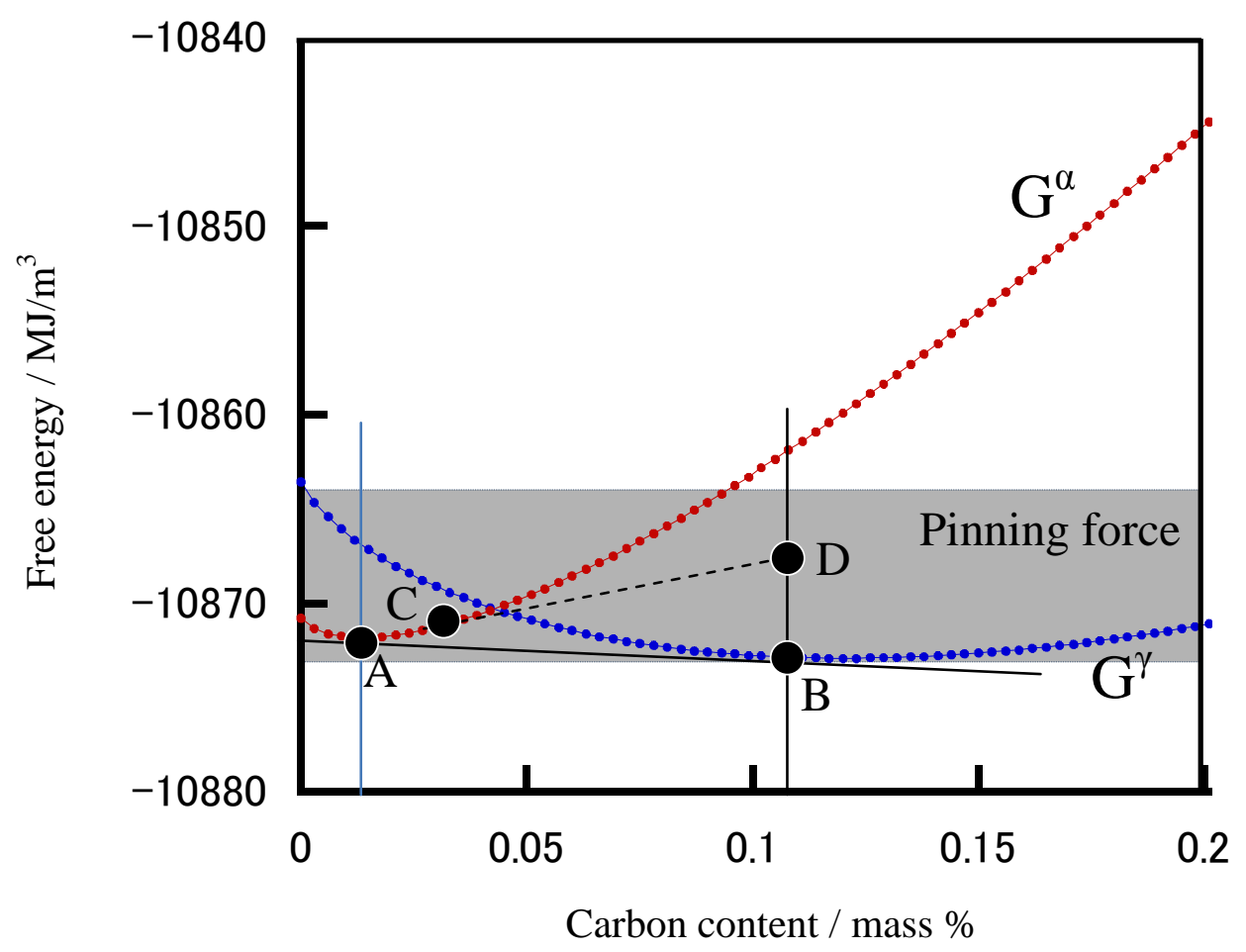

Fig. 5 Shigeharu Ukai, one column 


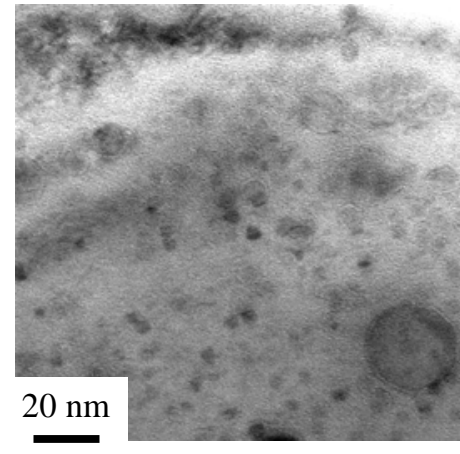

0 mass \% Ni

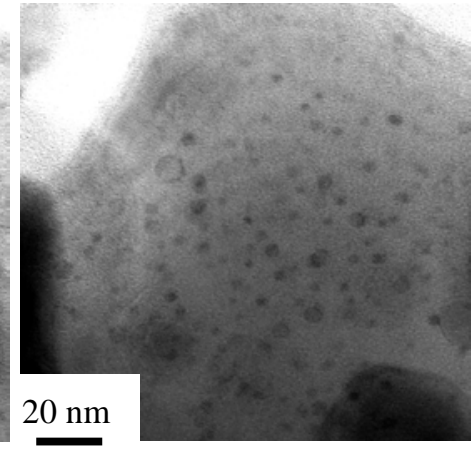

0.5 mass \% Ni

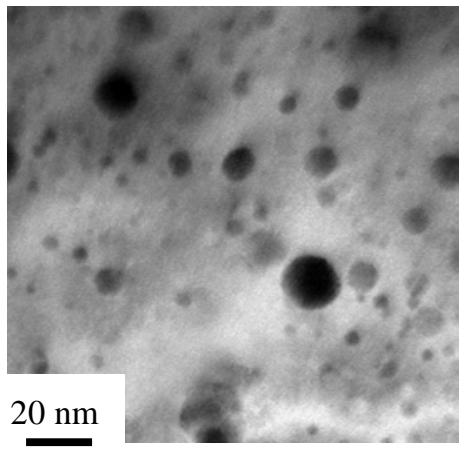

1.0 mass $\% \mathrm{Ni}$

Fig. 6 Shigeharu Ukai, two column 